\title{
Mortality assessment of patients with pancreatic cancer in Mexico, 2000-2014
}

\author{
Omar González-Santiago, Myrna L Yeverino-Gutiérrez, María del Rosario González-González, Ruth Corral-Symes and \\ Pilar C Morales-San-Claudio
}

Autonomous University of Nuevo León (UANL), School of Chemical Sciences, PhD in Pharmacy, San Nicolás de los Garza, Nuevo León 66455, Mexico

Correspondence to: Omar González Santiago. Email: omar.gonzalezst@uanl.edu.mx and omargs28@yahoo.com

\begin{abstract}
The five-year survival rate remains low for pancreatic cancer (PC). The objective of this study was to describe PC mortality rates in Mexico and its seven socioeconomic regions. The data for the deaths were obtained from the National Institute of Statistics and Geography databases. The adjusted rates were calculated using the world standard population. During the study period, the average mortality rate was 4.29 per 100,000 inhabitants. By gender, the rate was 4.35 and 4.29 per 100,000 inhabitants for men and women, respectively. Socioeconomic region 7 had the highest mortality rates. There was a significant decline in mortality rates in all of the groups.
\end{abstract}

Keywords: cancer, mortality rate, pancreas, Mexico

ecancer 2017, 11:788 https://doi.org/10.3332/ecancer.2017.788

Copyright: (c) the authors; licensee ecancermedicalscience. This is an Open Access article distributed under the terms of the Creative Commons Attribution License (http://creativecommons.org/licenses/by/3.0), which permits unrestricted use, distribution, and reproduction in any medium, provided the original work is properly cited. 


\section{Introduction}

Pancreatic cancer (PC) continues to be one of the malignancies with the worst prognosis once it has been diagnosed. The survival of people who suffer from it is only $5 \%$ at five years. This is attributed mainly to the delay in its diagnosis, since in the initial phases, it presents with nonspecific symptoms that make it difficult to diagnose such as jaundice, weight loss, abdominal pain and osteomalacia. Only $10 \%-20 \%$ of patients are diagnosed in the early stages when tumour resection and a possible cure are feasible [1].

There are multiple risk factors for the development of PC, including both environmental and genetic factors. Smoking falls into the first category. It is one of the main risk factors and therefore a preventable cause of PC, as are diets high in meats and fats, low levels of folate, obesity, diabetes mellitus, chronic pancreatitis, alcoholism, infection from Helicobacter pylori and a family history [2, 3].

According to data from GLOBOCAN 2012, PC causes more than 331,000 deaths per year, which places it among the top ten causes of cancer death [4]. In developing countries, it may even be the fourth leading cause of death from cancer and in developed countries such as the United States, it is expected to be the second leading cause of death from cancer by 2030 [5].

In the case of Mexico, cancer is the third leading cause of death, with cardiovascular diseases and complications of diabetes mellitus occupying the top two places [6]. Given the importance of this type of cancer, the objective of this study was to describe the PC mortality trend in Mexico by gender, age and socioeconomic region.

\section{Methods}

\section{Data}

PC deaths were obtained from the databases of the National Institute of Statistics and Geography (INEGI), which are freely accessible through its web portal. International Classification of Diseases (ICD-10) code C25 was used, which corresponds to malignant tumour of the pancreas. Information about the population of Mexico for the years 2000, 2005 and 2010 was obtained from the population censuses also reported by INEGI. The population for the remaining years was obtained by direct interpolation of the respective population censuses. The data used can be accessed at https://figshare.com/articles/Raw data Mortality assessment of patients with_pancreatic cancer in Mexico $2000 \quad 2014 / 5645788$.

\section{Statistical analysis}

The deaths were grouped by gender, three age groups ( $<40,40-59$ and $>60$ years) and socioeconomic region. There are seven socioeconomic regions in Mexico that range from the lowest (region 1) to the highest level of wealth (region 7), as classified by INEGI. The states that make up each of the regions are as follows: Region 1: Chiapas, Guerrero; Region 2: Campeche, Hidalgo, Puebla, San Luis Potosí, Tabasco, Veracruz; Region 3: Durango, Guanajuato, Michoacán, Tlaxcala, Zacatecas; Region 4: Colima, Mexico, Morelos, Nayarit, Querétaro, Quintana Roo, Sinaloa, Yucatan; Region 5: Baja California, Baja California Sur, Chihuahua, Sonora, Tamaulipas; Region 6: Aguascalientes, Coahuila, Jalisco, Nuevo León; and Region 7: Mexico City.

The adjusted mortality rate for each group was calculated per 100,000 inhabitants using the direct method and the world standard population. The difference between the means of the groups was analysed with the Student's $t$-test. The mortality trend was estimated with a logarithmic regression of the adjusted rates and it was evaluated with the Student's $t$-test where the alternative hypothesis is the slope not equal to 0 . The annual percentage change (APC) was estimated with the following formula: APC $=\left(e^{m}-1\right) * 100$ where $m$ is the slope that was previously obtained in the logarithmic regression [7, 8]. NCSS version 11 statistical software was used for the analyses.

\section{Ethical considerations}

The present study did not require the approval of the ethics committee because it is a retrospective study that used freely and publicly accessible data. INEGI databases do not allow or publish the identity of individuals. 


\section{Results}

During the study period, a total of 50,748 deaths due to PC were recorded. This represents $0.64 \%$ of all deaths in Mexico (Table 1 ), where the female gender, the 40-59 age group and the inhabitants of socioeconomic region 7 had the highest mortality percentages (0.77\%, $0.79 \%$ and $0.77 \%$, respectively).

On the other hand, the average adjusted mortality rate during the period was 4.29 per 100,000 inhabitants. By gender, the rate was 4.35 and 4.29 per 100,000 inhabitants for men and women, respectively (Table 2). The >60 age group and the inhabitants of region 7 had the highest mortality rates (27.1 and 6.1 per 100,000 inhabitants, respectively). The individuals that had lower rates were those $<40$ and the inhabitants of socioeconomic region 1 ( 0.12 and 3.04 per 100,000 inhabitants, respectively)

The temporal behaviour of the mortality rates by gender, age and socioeconomic region is presented in Figure 1. In all the groups studied, a downward trend in mortality rates is observed. With the exception of the $<40$ age group and the inhabitants of region $1(p=0.50$ and $p=0.39$, respectively), the rest of the groups had significant declines (Table 2 ). In general, the APC was $-1.08 \%$. By gender, this was -0.87 and -0.89 for men and women, respectively. The age group $<40$ had the lowest APC while the groups aged $40-60$ and $>60$ had similar APC ( $-1.09 \%$ and $-1.08 \%$, respectively). By socioeconomic region, the inhabitants of region 5 had the highest APC $(-1.74 \%)$, while those in region 1 had the lowest APC (0.3\%).

\section{Discussion}

In this study, PC mortality in Mexico was analysed. Previous studies in Mexico have shown that this type of cancer is in the sixth position in cancer mortality rates in men and the seventh in women [9]. Worldwide, the PC mortality rate is highly variable. Our results are similar to those of the population of China and Hong Kong, below those of the United States and some countries in Europe [10], and above those of Iran [11]. The causes of these differences at an international level are not well defined and more studies are needed in this area.

Table 1. Total pancreatic cancer deaths in Mexico.

\begin{tabular}{|c|c|c|c|c|}
\hline \multicolumn{2}{|c|}{ Variable } & \multirow{2}{*}{$\frac{\text { Pancreatic cancer }}{50,748}$} & \multirow{2}{*}{$\begin{array}{c}\text { Total deaths } \\
7,936,677\end{array}$} & \multirow{2}{*}{$\frac{\% \text { of total }}{0.64}$} \\
\hline Total & & & & \\
\hline \multicolumn{5}{|l|}{ Gender } \\
\hline & Male & 23,883 & $4,421,511$ & 0.54 \\
\hline & Female & 26,863 & $3,510,803$ & 0.77 \\
\hline \multicolumn{5}{|l|}{ Age } \\
\hline & $<39$ & 1,287 & $1,575,865$ & 0.08 \\
\hline & $40-59$ & 11,845 & $1,498,001$ & 0.79 \\
\hline & $>60$ & 37,575 & $4,824,822$ & 0.78 \\
\hline \multicolumn{5}{|c|}{ Socioeconomic region } \\
\hline & 1 & 3,774 & 775,916 & 0.49 \\
\hline & 2 & 8,408 & $1,579,108$ & 0.53 \\
\hline & 3 & 6,672 & 977,489 & 0.68 \\
\hline & 4 & 9,743 & $1,553,078$ & 0.63 \\
\hline & 5 & 6,500 & 964,121 & 0.67 \\
\hline & 6 & 8,262 & $1,134,256$ & 0.73 \\
\hline & 7 & 7,345 & 952,709 & 0.77 \\
\hline
\end{tabular}


Table 2. APC in PC mortality rate.

\begin{tabular}{|c|c|c|c|c|c|}
\hline \multirow{2}{*}{\multicolumn{2}{|c|}{ Variable }} & \multicolumn{2}{|c|}{ Period } & \multirow{3}{*}{$\begin{array}{c}\text { (Annual percentage } \\
\text { change) }\end{array}$} & \multirow{3}{*}{$\frac{\mathbf{P} \text { value treno }}{<0.01}$} \\
\hline & & \multirow{2}{*}{$\begin{array}{r}2000 \\
4.46 \\
\end{array}$} & \multirow{2}{*}{$\begin{array}{r}2014 \\
3.94 \\
\end{array}$} & & \\
\hline Total & & & & & \\
\hline \multicolumn{6}{|c|}{ Gender } \\
\hline & Male & 4.39 & 4.02 & -0.89 & 0.01 \\
\hline & Female & 4.52 & 3.85 & -0.87 & $<0.01$ \\
\hline \multicolumn{6}{|l|}{ Age } \\
\hline & $<40$ & 0.13 & 0.13 & 0.4 & 0.50 \\
\hline & $40-60$ & 4.24 & 3.81 & -1.09 & $<0.01$ \\
\hline & $>60$ & 28.39 & 24.78 & -1.08 & $<0.01$ \\
\hline \multicolumn{6}{|c|}{ Region } \\
\hline & 1 & 2.83 & 2.91 & 0.3 & 0.39 \\
\hline & 2 & 3.47 & 3.30 & -1.17 & $<0.01$ \\
\hline & 3 & 4.79 & 3.90 & -1.02 & $<0.01$ \\
\hline & 4 & 3.91 & 3.61 & -0.65 & 0.04 \\
\hline & 5 & 5.41 & 4.48 & -1.74 & $<0.01$ \\
\hline & 6 & 5.32 & 4.57 & -1.25 & $<0.01$ \\
\hline & 7 & 6.40 & 5.66 & -1 & 0.01 \\
\hline
\end{tabular}

In terms of mortality by gender, several studies have reported a significant difference between men and women, with the former having higher mortality rates [12]. It should be noted that in our case there were no statistically significant differences ( $p=0.48)$, and the causes of this result are not clear, as in Mexico the prevalence of smoking, one of the main risk factors, in men is almost double that of women [13]. It is likely that other associated factors that could contribute to this observation are the higher prevalence of obesity $(75.6 \%$ vs $69.4 \%)$ and diabetes $(10.3 \%$ vs $8.4 \%)$ in women [14].

The wealthiest socioeconomic regions in Mexico have the highest mortality rates. As previously mentioned, the wealthiest and therefore the most developed countries are those with the highest mortality rates. It is likely that this global pattern also applies at a regional level in each country. In addition, in developed countries, the proportion of elderly people is higher and if we consider that age is an important factor for the development of PC, this could explain in part the higher mortality rate in Mexico's socioeconomic region 7. In this region, the proportion of elderly people (age $>65$ ) is higher than in the rest of the regions.

Unlike other countries such as Korea, Spain, France and Russia [10], in which there have been significant increases in mortality rates for this type of cancer, the results in this study showed a significant decline $(p<0.01)$ in mortality rates. Our results are consistent with what has been observed in countries like Iran, the United States and the United Kingdom [10, 11]. In the case of Mexico, this decrease could be due to improvements in PC detection techniques and greater access to treatments. 


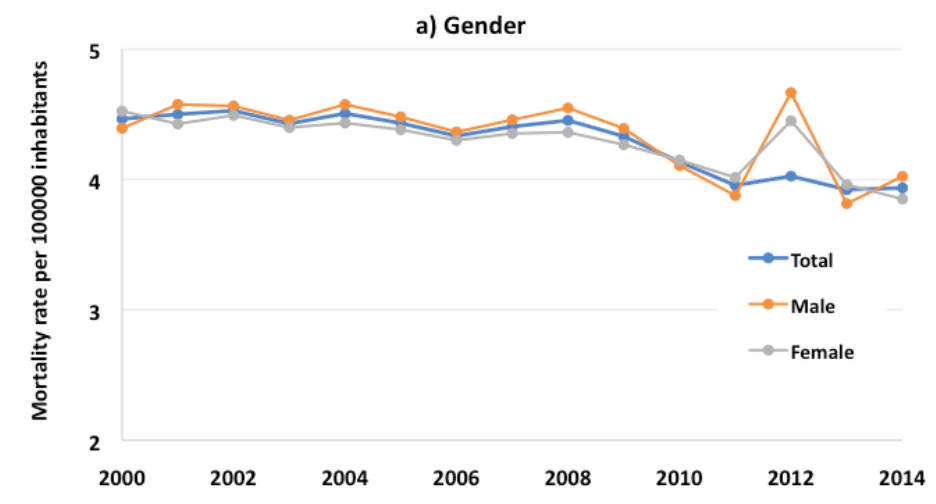

b) Age

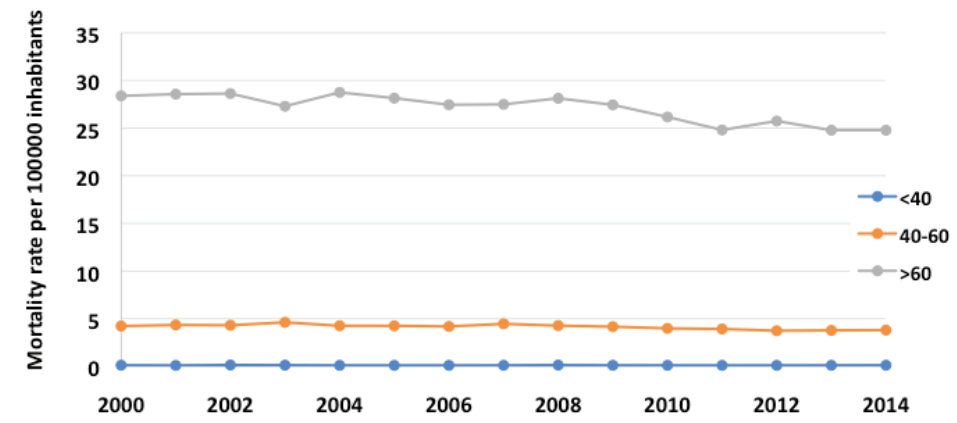

c) Region

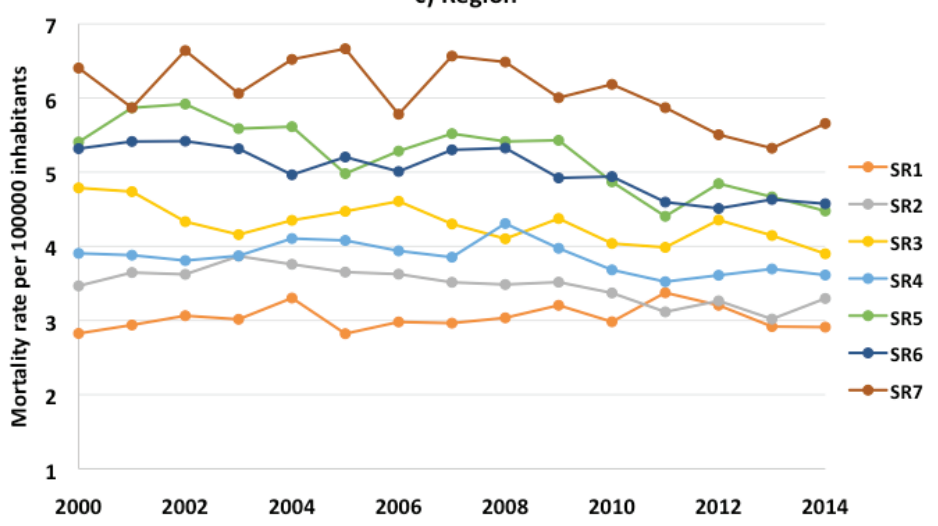

Figure 1. Pancreas mortality rates in Mexico: a) gender, b) age and c) socioeconomic region.

\section{Conclusion}

The average PC mortality rate in Mexico for the period 2000-2014 was 4.29 per 100,000 inhabitants and showed a significant downward trend. Socioeconomic region 7 had the highest mortality rates. 


\section{Conflicts of interest}

The authors declare that there is no conflict of interest.

\section{Author contributions}

Conception, design: OGS

Acquisition of data, statistical analysis: MLYG, MRGG

Interpretation of results: all authors

Manuscript writing and revising: RCS, PCMSC

Manuscript review: all authors

\section{References}

1. Poruk KE, Firpo MA, and Adler DG, et al (2013) Screening for pancreatic cancer: why, how, and who? Ann Surg 257(1) 17-26 https://doi.org/10.1097/SLA.0b013e31825ffbfb

2. Hart AR, Kennedy H, and Harvey I (2008) Pancreatic cancer: a review of the evidence on causation Clin Gastroenterol Hepatol 6(3) 275-282 https://doi.org/10.1016/j.cgh.2007.12.041 PMID: 18328435

3. Maitra A and Hruban RH (2008) Pancreatic cancer Annu Rev Pathol 3 157-188 https://doi.org/10.1146/annurev.pathmechdis.3.121806.154305

4. Ferlay J, Soerjomataram I, and Ervik M, et al (2013) GLOBOCAN 2012 v1.0, cancer incidence and mortality worldwide: IARC cancer base No. 11. Available from: http://globocan.iarc.fr/Default.aspx

5. Rahib L, Smith BD, and Aizenberg R, et al (2014) Projecting cancer incidence and deaths to 2030: the unexpected burden of thyroid, liver, and pancreas cancers in the United States Cancer Res 74(11) 2913-2921 https://doi.org/10.1158/0008-5472.CAN14-0155 PMID: 24840647

6. I N E G I (2016) Principales causas de muerte en México. Available from: http://www3.inegi.org.mx/sistemas/sisept/Default. aspx?t=mdemo125\&s=est

7. Moon EK, Park HJ, and Oh CM, et al (2014) Cancer incidence and survival among adolescents and young adults in Korea PLoS ONE 9(5) e96088 https://doi.org/10.1371/journal.pone.0096088 PMID: 24789075 PMCID: 4006908

8. Borges AKDM, Miranda-Filho A, and Koifman S, et al (2017) Thyroid cancer incidences from selected South America populationbased cancer registries: an age-period-cohort study J Glob Oncol https://doi.org/10.1200/JGO.17.00024

9. Rizo-Ríos P, González-RiveraA, and Sánchez-Cervantes F, et al (2015) Tendencia de la mortalidad por cáncer en México:1990-2012 Evidencia Medica e Investigación en Salud 8(1) 5-15

Rizo-Ríos P, González-Rivera A, and Sánchez-Cervantes F, et al (2015) Trends in cancer mortality in Mexico: 1990-2012 Evidencia Medica e Investigación en Salud 8(1) 5-15 (Engl. Transl.)

10. Katanoda K and Yako-Suketomo H (2010) Comparison of time trends in pancreatic cancer mortality (1990-2006) between countries based on the WHO mortality database Jpn J Clin Oncol 40(6) 601-602 https://doi.org/10.1093/jico/hyq089 PMID: 20508075 
11. Pourhoseingholi MA, Pourhoseingholi A, and Vahedi M, et al (2011) Decreased trend of pancreatic cancer mortality in Iran Asian Pac J Cancer 12(1) 153-155

12. Lucas AL, Malvezzi M, and Carioli G, et al (2016) Global trends in pancreatic cancer mortality from 1980 through 2013 and predictions for 2017 Clin Gastroenterol Hepatol 14(10) 1452-1462 https://doi.org/10.1016/j.cgh.2016.05.034 PMID: 27266982 PMCID: $\underline{5028258}$

13. Reynales-Shigematsu LM, Guerrero-López CM, and Lazcano-Ponce E, et al (2012) Encuesta Nacional de Adicciones 2011: Reporte de Tabaco 89

14. Hernandez-Avila M, Rivera-Dommarco J, and Shamah-Levy T, et al (2016) Encuesta Nacional de Salud y Nutrición de medio camino 2016 (ENSANUT MC 2016) 151 Available from: http://www.gob.mx/cms/uploads/attachment/file/209093/ENSANUT.pdf 